Int. J. Electrochem. Sci., 16 (2021) Article ID: 210622

\title{
Enhancing the Inhibition Effect and Adsorption Efficiency of Ethoxylated Dodecyl Alcohols on Corrosion of 316 Stainless Steels in $2 \mathrm{M} \mathrm{HCl}$
}

\author{
M. Abdallah ${ }^{1,2, *}$, M. Alfakeer ${ }^{3}$, Arej S Al-Gorair ${ }^{3}$, A. Al Bahir ${ }^{4}$, M. Sobhi ${ }^{2,5}$ \\ ${ }^{1}$ Chem. Depart. Faculty of Appl. Sci., Umm Al-Qura Univ.,Makkah, Saudi Arabia \\ ${ }^{2}$ Chem. Depart. Faculty of Sci, Benha Univ., Benha, Egypt \\ ${ }^{3}$ Chem. Depart., College of Sci., Princess Nourah bint Abdulrahman Univ., Riyadh, Saudi Arabia \\ ${ }^{4}$ Chem. Depart. Faculty of Sciences, King Khalid Univ., Abha, Saudi Arabia \\ ${ }^{5}$ Chem. Depart. Faculty of Sci., Tabuk University, Tabuk, Saudi Arabia \\ *E-mail: metwally555@yahoo.com
}

doi: $10.20964 / 2021.06 .09$

Received: 6 February 2021 / Accepted: 26 March 2021 / Published: 30 April 2021

\begin{abstract}
The inhibiting impact of three molecules of ethoxylated dodecyl alcohols (EDA) with different ethylene oxide units against the corrosion of 316 stainless steel (316SS) in $2 \mathrm{M} \mathrm{HCl}$ solutions was examined. Electrochemical tests such as galvanostatic, potentiodynamic anodic polarization and electrochemical impedance spectroscopy were applied to assign the electrochemical parameters. All the tests used confirm the inhibitory action of EDA molecules. The inhibition efficacy increasing with increasing the concentrations of EDA molecules, increase of ethylene oxide units and reducing at elevated temperature. The inhibition was expounded by the forming of adsorbed film on the surface 316SS through the EO unit while the hydrocarbon parts protrude brush -like into the solution. This adsorption obeyed Temkin's isotherm. Galvanostatic polarization demonstrates that the EDA molecules act as mixed inhibitors. The thermodynamic kinetics parameters for activation processes were determined and expounded. EDA molecules reduces the pitting attack of $316 \mathrm{SS}$ in $\mathrm{NaCl}$ solution from the transmitting of the pitting potential to the noble trend.
\end{abstract}

Keywords: Ethoxylated dodecyl alcohols, 316 stainless steel, Inhibitors, Pitting, Adsorption, SEM.

\section{$\underline{\text { FULL TEXT }}$}

(C) 2021 The Authors. Published by ESG (www.electrochemsci.org). This article is an open access article distributed under the terms and conditions of the Creative Commons Attribution license (http://creativecommons.org/licenses/by/4.0/). 